

\section{RIGHT BRAIN METHOD}

ABDUL AZIZ, SP.d, MP.d

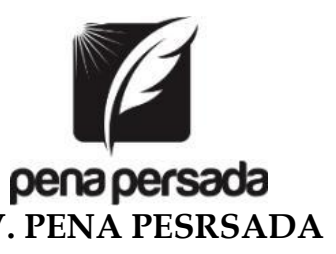




\section{RIGHT BRAIN METHOD}

Penulis :

Abdul Aziz, SP.d, MP.d

ISBN :978-623-6837-07-8

Design Cover :

Retnani Nur Briliant

Layout :

Hasnah Aulia

\section{Penerbit CV. Pena Persada}

Redaksi :

Jl. Gerilya No. 292 Purwokerto Selatan, Kab. Banyumas Jawa Tengah

Email : penerbit.penapersada@gmail.com

Website : penapersada.com

Phone : (0281) 7771388

Anggota IKAPI

All right reserved

Cetakan pertama : 2020

Hak cipta dilindungi oleh undang-undang.

Dilarang memperbanyak karya tulis ini dalam bentuk dan cara apapun tanpa ijin penerbit 


\section{KATA PENGANTAR}

Dengan memanjatkan puji dan syukur kehadirat Allah SWT, maka buku Metode Otak Kanan terselesaikan dengan baik. Buku ini disusun untuk memberikan pengetahuan pembelajaran metode otak kanan.

Metode Otak kanan bekerja dengan menggunakan kemampuan long term memory sehingga saat melihat suatu gambar atau yang lainnya akan terekam lama dalam ingatan. Misalnya saat melihat suatu lukisan, tentu kita tidak akan langsung melupakannya tapi kita akan mampu membayangkan teksturnya, bentuknya, warnanya, gelap terangnya, juga perkiraan seberapa besar dan maknanya. Hal ini terjadi karena sistem kerja otak kanan yang mampu mengolah memori dalam jangka panjang.

Saya menyampaikan terima kasih kepada seluruh pihak yang telah membantu terbitnya buku ini, khususnya tim penyusun. Semoga upaya yang telah

dicurahkan bermanfaat bagi pembaca di Indonesia, khususnya

Dengan adanya buku ini bisa diterapkan para pendidik untuk menerapkan metode otak kanan dalam pembelajaran terbuka. Untuk kritik dan saran dari teman sejawat sekalian, guna perbaikan penyusunan buku ini ke depan. 


\section{DAFTAR ISI}

KATA PENGANTAR ............................................................

DAFTAR ISI …....................................................................... iv

BAB 01 OTAK KANAN

A. Pengertian Otak Kanan ....................................................... 1

B. Struktur Otak Kanan .................................................................. 1

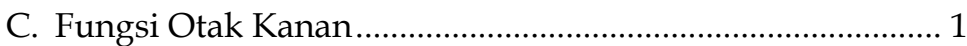

D. Cara Kerja Otak Kanan ............................................................ 2

BAB 02 PENGERTIAN OTAK KANAN, STRUKTUR, FUNGSI DAN CARA KERJANYA

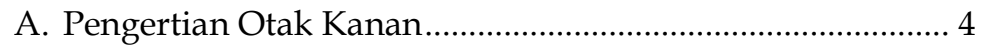

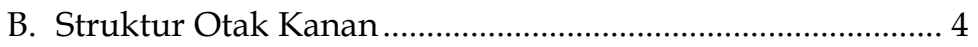

C. Fungsi Otak Kanan............................................................... 5

D. Cara Kerja Otak Kanan ………………………..................... 5

E. Ketahui Fungsi Otak Kiri dan Kanan ................................... 6

F. Mengenal Fungsi Otak Kiri dan Otak Kanan Lebih

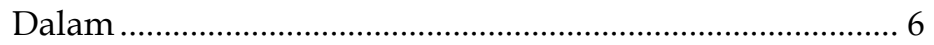

G. Benarkah Tiap Manusia Memiliki Sisi Otak yang Dominan 8

BAB 03 CIRI-CIRI ANAK YANG MENGGUNAKAN OTAK KANAN

A. Ciri-Ciri Anak Menggunakan Otak Kanan ........................... 10

B. Tiga Tips Berikut Ialah Bagaimana Mengoptimalkan Otak Kanan dan Kiri

BAB 04 KIDAL BUKAN BERARTI DOMINAN OTAK KANAN

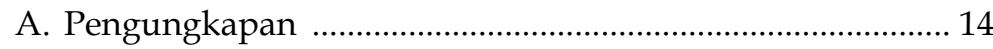

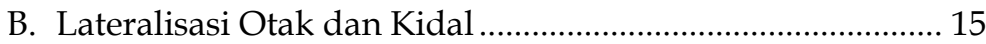

BAB 05 FUNGSI OTAK KANAN

A. Fungsi Otak ....................................................................... 18

B. Keajaiban Otak Kanan Pertama Kali Diketahui Pada Tahun 1981

C. Otak Kanan atau Otak Kiri Lebih Kuat : Ternyata Hanya Mitos

D. Dari Mana Asal Mitos Otak Kanan dan Otak Kiri Lebih Kuat 20 
E. Apakah Salah Satu Sisi Otak Lebih Kuat Dari Sisi Otak Lain

F. Kenapa Mitos Otak Kanan dan Otak Kiri Lebih Kuat "Terus Berkembang"

G. Apa yang Harus Dipahami Tentang Mitos Otak

Kanan dan Otak Kiri "Lebih Kuat"

BAB 06 CARA MELATIH OTAK KANAN

\section{UNTUK MEMPERTAJAM INGATAN SECARA} OPTIMAL

A. Melatih Otak Kanan ............................................................ 22

B. Kinerja dan Karakteristik Otak Kanan .................................. 22

BAB 07 TIPS MEMILIH JURUSAN YANG COCOK UNTUK PENGGUNA OTAK KANAN

A. Jurusan Sesuai Dengan kemampuan Otak Kanan 25

BAB 08 KISAH ORANG-ORANG OTAK KANAN

A. Orang-Orang Menggunakan Otak Kanan 27

B. Refleksi Orang Menggunakan Otak Kanan 30

BAB 09 PENEMU ROGER W SPERRY

A. Penemuan Teori Otak Kiri dan Otak Kanan Roger W Sperry

BAB 10 OTAK KITA YANG TIDAK SEIMBANG (ASIMETRIS)

A. Perkembangan Otak Kanan dan Kiri Simetris .................... 35

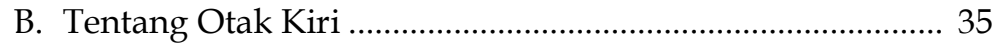

C. Tentang Otak Kanan ................................................................ 36

BAB 11 APAKAH OTAK KANAN LEBIH BAIK DARI PADA OTAK KIRI

A. Lebih Baik Otak Kiri Atau Otak Kanan 37

B. Hampir Setiap Waktu, Kedua Belahan Otak Kita Aktif 38

C. Gunakan Kedua Belahan Otak Anda 39

BAB 12 ANAK DOMINAN OTAK KANAN? YUK BANTU CARA BELAJARNYA, DEARS

A. Anak Dominan Otak Kanan 40

BAB 13 MENYEIMBANGKAN OTAK KANAN DAN OTAK KIRI DENGAN MUSIK KLASIK

A. Menyeimbangkan Otak Kiri dan Otak Kanan 45 
B. Perbedaan Fungsi Otak kanan dan Otak Kiri........................ 47

C. Perbedaan Fungsi Otak kanan dan Otak Kiri ........................ 48

D. Perbedaan Otak kanan dan Otak Kiri ..................................... 50

BAB 14 MAKSIMALKAN FUNGSI OTAK KANAN \& OTAK KIRI

A. Bagian Otak Mana yang Paling Dominan Pada ................... 51 Anda

\section{BAB 15 FUNGSI OTAK KANAN LAHIRKAN} KREATIVITAS SPEKTAKULER

A. Ilutrasi Otak Manusia (Istimewa) 53

BAB 16 CIRI-CIRI ANAK YANG DIDIMINASI OTAK KANAN

A. Anak Dominasi Otak Kanan 55

BAB 17 OTAK KANAN VS OTAK KIRI

A. Otak Kanan VS Otak Kiri ………………….......................... 57

B. Benarkah Perbedaan Antara Otak Kanan dan ..................... 57

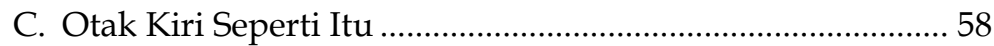

D. Mana yang Lebih Baik? Belahan Otak Kanan Atau Belahan Otak Kiri .................................................................... 59

E. Cara Mengetahui Dominasi Belahan Otak............................59

F. 4Cara Menyeimbangkan Otak Kanan dan Kiri ..................... 61

BAB 18 KEMBANGKAN FUNGSI OTAK KANAN DENGAN CARA KREATIF

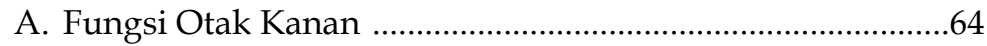

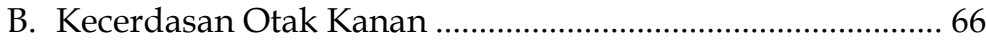

C. 4 Cara Melatih Otak Kanan Agar Tidak Cepat Pikun ........ 68

BAB 19 TINGKATKAN KEMAMPUAN OTAK KANAN ANAK DENGAN METODE BIODRAWING

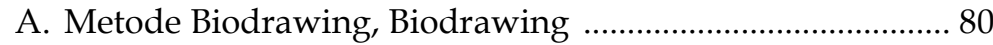

B. Apa itu Metode Biodrawing ………............................................ 80

C. Berbagai Keunggulan Metode Biodrawing........................... 80

D. Cara Menstimulasi Metode Biodrawing Pada Anak ........... 81

BAB 20 KUASAI AL-QURAN DAN SAINS DENGAN METODE OTAK KANAN

A. Menguasai Al-Quran dengan Otak Kanan ........................ 83

BAB 21 ANAK DENGAN OTAK KANAN: CIRI-CIRI DAN CARA MEMBANTUNYA DALAM BELAJAR vi 


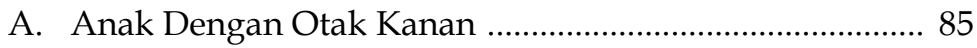

B. Cara Bekerja Otak Kanan...................................................... 88

C. Perbandingan Kerja Otak Kiri dan Otak Kanan .............. 89

D. Perbedaan Kombinasi Kontinum Otak dan Indera

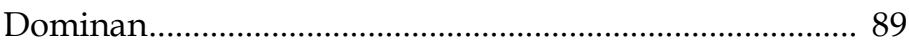

E. Membantu Anak Otak Kanan Belajar ................................. 90

BAB 22 BAGAIMANA CARA BELAJAR ANAK-ANAK YANG DOMINAN OTAK KANAN

A. Cara Belajar Anak yang Dominan Otak Kanan 92

BAB 23 MENGENAL FUNGSI OTAK KANAN, SI KREATIF YANG BIKIN ANDA SUKA KESENIAN

A. Mengenai Fungsi Otak Kanan .......................................... 96

B. Fungsi Otak Kanan yang Bikin Anda Kreatif ................... 96

C. Bagaimana Cara Menajamkan Fungsi Ota Kanan ........... 97

BAB 24 CARA MENGAKTIFKAN OTAK KANAN DENGAN MAKSIMAL

A. Cara Mengaktifkan Otak Kanan ........................................ 99

BAB 25 MENGEMBANGKAN OTAK KANAN ANAK

A. Mengembangkan Otak Anak .............................................. 104

B. Metode Tsaqifa, Memadukan Otak Kanan dan Kiri ............ 105

BAB 26 KEMBANGKAN KREATIVITAS DAN OTAK KANAN ANAK DENGAN MARBEL MUSIK

A. Kreativitas Marbel Musik Dengan Otak Kanan 107

BAB 27 MENYIASATI ANAK YANG DOMINAN OTAK KANAN

A. Menyiasati Anak Dominan Otak Kanan 110

B. 7 Cara Menstimulasi Otak Kanan Agar Kreatif 111

BAB 28 DUNIA PEMBELAJARAN OTAK KANAN

A. Pembelajaran Otak Kanan 114

BAB 29 ANAK DOMINAN MENGGUNAKAN OTAK KANAN

A. Anak Dominan Otak Kanan 117

B. Cara-Cara Untuk Meningkatkan Kemampuan Otak Kanan Agar Lebih Kreatif

BAB 30 SENAM OTAK, CARA MUDAH MELATIH OTAK KANAN \&KIRI ANAK SUPAYA SEIMBANG

A. Tumbuhkan Anak Cerdas Dengan Metode Belajar 
BAB 31JENIS PERMAINAN ASAH OTAK KANAN KIRI ANAK

A. Permainan Otak Kanan dan Kiri Anak ................................. 126 BAB 32 MENGEMBANGKAN OTAK KANAN ANAK .

A. Mengembangkan Otak Kanan ............................................. 129

B. Bagaimana Cara Menggunakan Kekuatan Otak Kanan 130

C. Selaraskan Otak Kanan dan Otak Kiri .................................... 132

D. 7 Cara Menghadapi AnakDominan Otak Kanan Yang Kesulitan Dalam Belajar

BAB 33 CARA MELATIH OTAK KANAN UNTUK MEMPERTAJAM INGATA

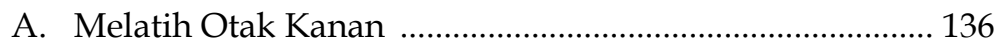

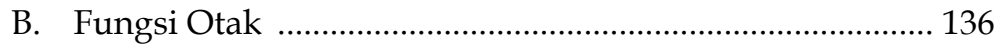

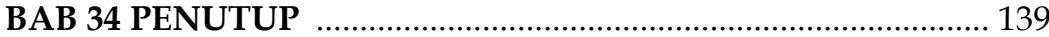

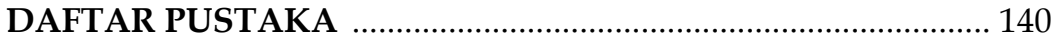




\section{BAB 01 OTAK KANAN}

\section{A. Pengertian Otak Kanan}

Otak manusia terbagi menjadi otak besar dan otak kecil. Otak besar terbagi menjadi 2 yaitu otak kanan dan otak kiri. Dalam dunia kesehatan, otak kanan disebut Right helisphere. Sesuai namanya, bagian otak ini secara anatomi berada pada belahan kanan dari otak besar yang berfungsi mengatur dan bertanggung jawab pada seluruh aktifitas serta kesehatan tubuh bagian kanan. Tidak hanya berfungsi mengatur seluruh aktifitas dan kesehatan tubuh bagian kanan, otak kanan junga mengatur berbagai akifitas dan ekspresi yang berhubungan dengan emosi.

\section{B. Struktur Otak Kanan}

Struktur otak kanan terdiri dari jutaan jaringan dan jutaan syaraf yang membentuk seperti setengah lingkaran yang agak pipih dan memiliki dua jenis sel, yaitu glia dan neuron. Glia berfungsi untuk menunjang dan melindungi neuron, sedangkan neuron berfungsi untuk membawa informasi, keduanya saling berkomunikasi dan mengirimkan berbagai bahan kimia ke seluruh tubuh yang disebut dengan neurotransmiter. Pada bagian dalam strukturnya terdapat bagian berwarna putih yang disebut dengan basal nuclei yang berfungsi untuk perencanaan dan pembelajaran yang bertugas untuk memberikan perintah kepada sel tubuh yang lain.

\section{Fungsi Otak Kanan}

Adapun fungsi otak kanan diantaranya yaitu:

1. Berfungsi dalam perkembangan kecerdasan emosi atau EQ (emotional quotient) seperti pengendalian emosi dan sosialisasi.

2. Kemampuan berinteraksi dengan manusia lain, intuitif, kemampuan merasakan dan memadukan. 
3. Mengatur ekspresi tubuh seperti menyanyi, menari, dan melukis.

4. Melakukan tugas matematika tentang perbandingan dan estimasi.

5. Membantu membayangkan visual secara lengkap dan mengekspresikan apa yang dilihat.

6. Mengontrol otot-otot di bagian kiri tubuh.

7. Berperan dalam kemampuan berbahasa karena memiliki kemampuan memori jangka panjang.

8. Berhubungan dengan segala sesuatu yang membutuhkan kreatifitas dalam pelaksanaannya.

9. Bertanggung jawab atas kemampuan spasial; meliputi pengenalan wajah dan pengolahan musik.

10. Melakukan beberapa fungsi matematika, tapi hanya berupa perkiraan kasar dan perbandingan.

\section{Cara Kerja Otak Kanan}

1. Sel-sel yang terdapat pada fungsi otak kanan cenderung menggunakan kreatifitas untuk memecahkan suatu masalah. Sel-sel tersebut bisa berfikir sangat cepat, 1 detik saja otak kanan berhenti bekerja maka akan terjadi kerusakan pada seluruh bagian tubuh.

2. Otak kanan bekerja dengan menggunakan kemampuan long term memory sehingga saat melihat suatu gambar atau yang lainnya akan terekam lama dalam ingatan. Misalnya saat melihat suatu lukisan, tentu kita tidak akan langsung melupakannya tapi kita akan mampu membayangkan teksturnya, bentuknya, warnanya, gelap terangnya, juga perkiraan seberapa besar dan maknanya. Hal ini terjadi karena sistem kerja otak kanan yang mampu mengolah memori dalam jangka panjang.

3. Ribuan sel yang terdapat pada otak kanan sudah dibentuk sejak dalam kandungan untuk mampu bekerja dengan mengandalkan kreatifitas dan ingatan, hal ini yang mendukung dan menjurus pada berbagai fungsi otak kanan 
yang sangat berpengaruh dalam kecerdasan emosi seseorang.

4. Demikian penjelasan yang bisa kami sampaikan tentang Pengertian Otak Kanan, Struktur, Fungsi dan Cara Kerja Otak Kanan Pada Manusia Terlengkap. Semoga bermanfaat dan jangan lupa ikuti postingan kami berikutnya. Sampai jumpa 


\section{BAB 02 PENGERTIAN OTAK KANAN, STRUKTUR, FUNGSI DAN CARA KERJANYA}

\section{A. Pengertian Otak Kanan}

Di dalam otak manusia, itu terdapat bagian bagian otak manusia yang lebih kompleks lagi yakni otak besar serta otak kecil. Otak besar tersebut terbagi menjadi 2 belahan yaitu otak kanan serta otak kiri. Otak kanan di dalam dunia kesehatan disebut dengan Right helisphere, sesuai dengan namanya Otak kanan ini merupakan bagian yang secara anatomi berada pada belahan kanan dari otak besar yang mengatur serta juga bertanggung jawab pada seluruh aktifitas serta juga kesehatan tubuh bagian kanan.

Sebab itulah terkadang terdapat penyakit lumpuh atau juga struk pada sebagian belahan tubuh, hal tersebut terjadi karena tiap bagian diatur oleh bagian otak yang juga berbeda. Namun bukan sekedar itu saja tugas dari otak kanan melainkan juga berbagai akifitas serta ekspresi yang berhubungan dengan emosi.

\section{B. Struktur Otak Kanan}

Selanjutnya ialah mengenai strukturnya, tentu kamu bertanya tanya bukan? Bagaimana bentuk serta gambaran jaringan di dalamnya? Struktur otak kanan ini terdiri dari jutaan jaringan serta jutaan syaraf yang membentuk seperti setengah lingkaran yang agak pipih dan juga memiliki dua jenis sel, yakni glia serta neuron.

Glia ini memiliki fungsi untuk menunjang serta melindungi neuron, sedangkan untuk neuron ini memiliki tugas membawa informasi, mereka saling berkomunikasi serta mengirimkan berbagai bahan kimia ke seluruh tubuh yang disebut dengan sebutan neurotransmiter. Pada bagian dalam strukturnya itu terdapat bagian berwarna putih yang disebut dengan basal nuclei yang berguna untuk perencanaan serta 
pembelajaran yang bertugas untuk dapat memberikan perintah kepada sel tubuh yang lain.

\section{Fungsi Otak Kanan}

Tiap-tiap ciptaan Tuhan itu memiliki fungsi yang luar biasa serta berpengaruh pada tubuh secara keseluruhan, Sama juga dengan otak kanan, Adapun fungsi otak kanan pada tubuh kita ini sebagai berikut

1. Berfungsi didalam perkembangan kecerdasan emosi atau EQ (emotional quotient) seperti pengendalian emosi serta sosialisasi.

2. Kemampuan didalm interaksi dengan manusia lain, intuitif, kemampuan merasakan serta memadukan.

3. Ekspresi tubuh seperti misalnya menyanyi, menari, serta melukis.

4. Melakukan tugas matematika mengenai perbandingan serta estimasi.

5. Membantu dalam membayangkan visual dengan secara lengkap serta mengekspresikan apa yang dilihat.

6. Berperan di dalam kemampuan berbahasa sebab memiliki kemampuan memori jangka panjang.

7. Berhubungan juga dengan segala sesuatu yang membutuhkan kreatifitas di dalam pelaksanannya.

\section{Cara Kerja Otak Kanan}

Otak kanan ini memiliki fungsi sebagaimana yang telah dijelaskan sebab mempunyai cara kerja yang menjurus pada fungsi tersebut. Sel sel yang berada pada fungsi otak kanan tersebut cenderung menggunakan kreatifitas di dalam memecahkan suatu masalah. Sel sel itu bisa/dapat berfikir dengan sangat cepat, 1 detik saja otak kanan berhenti bekerja tentu hal tersebut akan terjadi kerusakan pada seluruh bagian tubuh.

Otak kanan ini bekerja dengan menggunakan kemampuan long term memory sehingga pada saat melihat suatu gambar akan terekam lama di dalam ingatan. Misalnya seperti pada saat melihat sebuah lukisan, tentu kamu tidak 
langsung melupakannya bukan? anda akan dapat mampu membayangkan teksturnya, bentuknya, warnanya, gelap terangnya, juga perkiraan seberapa besar serta apa maknanya. Hal itu terjadi disebabkan karena sistem kerja otak kanan yang mampu untuk mengolah memori dalam jangka panjang.

Ribuan sel yang terdapat di dalam otak kanan ini memang sudah dibentuk sejak dalam kandungan untuk mampu bekerja dengan mengandalkan kreatifitas serta ingatan, hal tersebut yang mendukung dan juga menjurus pada berbagai fungsi otak kanan yang sangat berpengaruh di dalam kecerdasan emosi seseorang.

Nah itulah penjelasan mengenai Pengertian Otak Kanan, Struktur, Fungsi dan Cara Kerjanya, semoga apa yang diuraikan dapat bermanfaat untuk anda, Terima kasih.

\section{E. Ketahui Fungsi Otak Kiri dan Otak Kanan}

Otak terbagi menjadi dua sisi, yaitu otak kiri dan otak kanan. Organ yang sangat penting dan kompleks ini memiliki bagian-bagian tertentu dengan fungsinya masing-masing pada tubuh.

Otak besar terdiri atas bagian otak kiri dan otak kanan yang penting untuk menjalankan aktivitas sehari-hari manusia. Penelitian menunjukkan, otak kiri lebih banyak digunakan untuk proses berpikir secara logika dan dalam berbahasa, sementara otak kanan lebih berperan untuk proses intuitif dan visual.

\section{F. Mengenal Fungsi Otak Kiri dan Otak Kanan Lebih Dalam}

Adanya dua belahan otak di kiri dan kanan mendasari adanya teori otak kiri dan otak kanan. Jika Anda lebih banyak berpikir secara metodis dan analitis, berarti otak kiri Anda mungkin lebih dominan. Sementara, jika sehari-harinya Anda terbiasa berpikir tentang hal yang kreatif atau artistik, berarti otak kanan Anda bisa jadi lebih dominan. Namun sebenarnya, kedua bagian otak tersebut saling melengkapi dan sama-sama memiliki peran yang penting. 
Berdasarkan perbedaan fungsi otak kanan dan kiri, terdapat teori yang menyatakan bahwa seseorang bisa didominasi otak kiri atau otak kanan dan hal ini kemudian berdampak pada kepribadian dan kemampuannya.

Berdasarkan teori tersebut, perbedaan apabila salah satu fungsi otak kanan atau otak kiri lebih dominan pada seseorang, dapat dilihat dari:

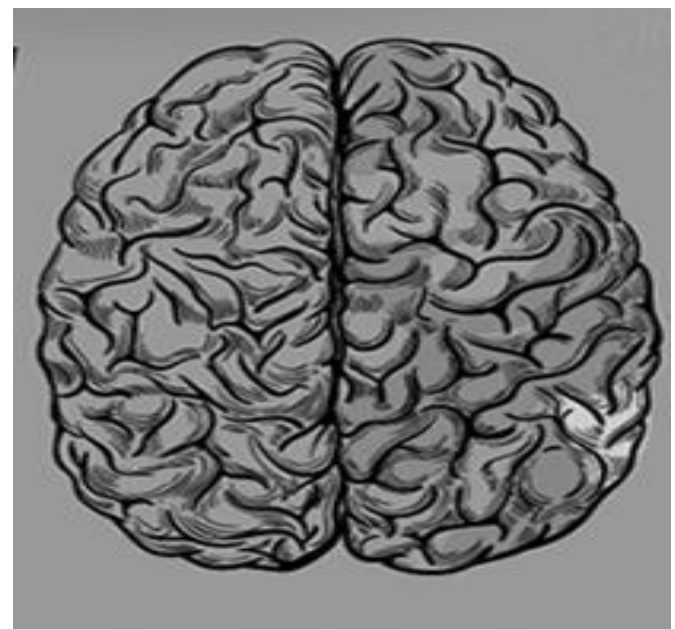

\section{Otak Kiri}

\section{Otak Kanan}

1. Lebih baik dalam 1. Banyak berimajinasi melakukan kegiatan seperti membaca,

2. Sering melamun mencari ide menulis, menghitung

2. Lebih banyak berpikir menggunakan logika

3. Lebih ahli dalam matematika

3. Cenderung menyukai seni

4. Lebih sering menggunakan intuisi dalam memahami sesuatu

4. Lebih mementingkan fakta 


\section{G. Benarkah Tiap Manusia Memiliki Sisi Otak yang Lebih Dominan}

Banyak pendapat terkait teori otak kanan dan otak kiri serta pengaruhnya terhadap bidang pekerjaan manusia. Teori tersebut menyatakan bahwa tiap bagian otak mengontrol cara berpikir yang berbeda-beda dan tiap bagian dapat menentukan karakteristik, bahkan jenis pekerjaan yang tepat untuk tiap orang. Namun apakah teori tersebut dapat dipertanggungjawabkan secara ilmiah?

Hasil pemindaian Magnetic Resonance Imaging (MRI) ternyata tidak mengindikasikan bahwa salah satu bagian otak lebih mendominasi atau memengaruhi kepribadian seseorang. Hasil penelitian yang dilakukan oleh seorang ahli saraf, tidak ditemukan bukti-bukti yang mendukung teori dominan otak kanan atau otak kiri.

Kedua sisi otak saling terhubung dan berkomunikasi. Orang yang otak kirinya lebih aktif memiliki jumlah jaringan saraf yang sama pada bagian kanan. Begitu pula sebaliknya.

Penelitian tersebut membenarkan bahwa tiap bagian otak memiliki fungsinya masing-masing. Misalnya, otak kanan bertugas untuk fokus mengikuti arahan, sedangkan otak kiri berperan menjalankan fungsi berbahasa. Namun, bukan berarti salah satu sisi otak lebih dominan. Dengan demikian tidak ada hubungan antara dominan otak kanan versus otak kiri terhadap tipe kepribadian manusia.

Otak kiri dan otak kanan sama-sama berperan aktif bagi manusia dalam menjalani aktivitasnya. Karenanya, akan lebih baik untuk memaksimalkan fungsi keduanya secara sinergis, daripada memilah-milah fungsinya secara terpisah.

Ini Beda Otak Kiri dan Otak Kanan Anda yang Perlu Diketahui Beda otak kiri dan kanan memang benar adanya

Perbedaan otak kanan dan otak kiri terletak dari tugas yang dikerjakannya Otak kita adalah organ yang luar biasa rumit. Hanya dengan berat sekitar $2 \mathrm{~kg}$, ada 100 miliar sel saraf dan 100 triliun sambungan sel saraf dalam otak. Sebagai pusat komando tubuh, secara garis besar otak membagi tugasnya 
menjadi dua kelompok, yaitu otak kanan dan otak kiri. Apa perbedaan otak kanan dan otak kiri? Perbedaan otak kanan dan otak kiri, terletak pada jenis pemikiran yang dihasilkan. Otak kanan, merupakan bagian otak yang memproses kreativitas untuk berimajinasi dan berpikir tentang seni. Sementara itu otak kiri lebih banyak memikirkan hal-hal yang analitis dan matematis.

Berdasarkan perbedaan keduanya yang cukup jelas ini, peneliti pun menyebutkan bahwa manusia memiliki satu sisi otak yang dominan. Benarkah demikian? Lebih jauh tentang perbedaan otak kanan dan otak kiri Otak kita secara garis besar dibagi menjadi dua bagian, atau yang dalam bahasa kedokteran, disebut dengan hemisfer. Masing-masing bagiannya mengontrol fungsi yang berbeda.

Secara fisik, otak kanan dan otak kiri tampilannya tidak jauh berbeda. Namun, ada perbedaan besar yang memisahkan keduanya. Perbedaan otak kanan dan otak kiri, terletak pada caranya memproses informasi yang masuk ke otak. Meski begitu, kedua bagian otak ini tidak bekerja sendiri-sendiri.

Teori tentang perbedaan otak kanan dan otak kiri ini pertama kali dikemukakan oleh seorang peneliti bernama Roger W. Sperry pada tahun 1960an. Berdasarkan teori Sperry, setiap orang memiliki kecenderungan untuk lebih memakai otak kanan atau otak kirinya. Berikut perbedaan masingmasing. (Parta Ibeng, 2020). 